\title{
Effect of Rosuvastatin on Outcomes in Chronic Haemodialysis Patients: Baseline Data from the AURORA Study
}

\author{
Bengt Fellström ${ }^{a}$ Hallvard Holdaas ${ }^{b}$ Alan G. Jardine ${ }^{c}$ Helen Rose $^{d}$ \\ Roland Schmieder ${ }^{\mathrm{e}}$ Wim Wilpshaar ${ }^{f}$ Faiez Zannad $^{\mathrm{g}}$ \\ on behalf of the AURORA Study Group

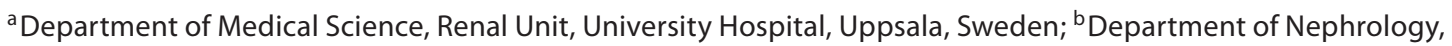 \\ Rikshospitalet, University of Oslo, Oslo, Norway; ' BHF Glasgow Cardiovascular Research Centre, University \\ of Glasgow, Glasgow; ${ }^{\text {d} A s t r a Z e n e c a, ~ M a c c l e s f i e l d, ~ U K ; ~}{ }^{e}$ Department of Nephrology and Hypertension, \\ Universitätsklinik, Erlangen-Nürnberg, Erlangen, Germany; f former AstraZeneca, Macclesfield, UK and \\ ${ }^{g}$ Clinical Investigation Centre INSERM (CIC), Hôpital Jeanne d'Arc, Toul, France
}

\section{Key Words}

Rosuvastatin - End-stage renal disease $\cdot$ Cardiovascular disease $\cdot$ Haemodialysis

\begin{abstract}
Background: Cardiovascular disease (CVD) is the leading cause of death in patients with end-stage renal disease (ESRD). Aims: AURORA (A study to evaluate the Use of Rosuvastatin in subjects On Regular haemodialysis: an Assessment of survival and cardiovascular events) is the first largescale international trial to assess the effects of statins on cardiovascular outcomes in patients with ESRD on chronic haemodialysis. Preliminary baseline data from the randomised population are presented. Methods: A total of 2,775 patients from 280 centres in 25 countries were randomised into the study. Patients aged $50-80$ years on regular chronic haemodialysis for at least 3 months before screening were eligible for inclusion. They were randomised 1:1 to receive either rosuvastatin $10 \mathrm{mg}$ or placebo daily and assessed throughout the study. Results: The mean age at baseline was 64 years. Most patients were male (62\%) and $85 \%$ were white. The median time since commencing renal
\end{abstract}

replacement was 32 months. Mean total cholesterol (TC) and low-density lipoprotein cholesterol (LDL-C) levels were 4.53 $\mathrm{mmol} / \mathrm{l}(175 \mathrm{mg} / \mathrm{dl})$ and $2.57 \mathrm{mmol} / \mathrm{l}(99 \mathrm{mg} / \mathrm{dl})$, respectively. Conclusion: Results from the AURORA trial will impact on the current guidelines and use of statins in this patient population.

Copyright $\odot 2007$ S. Karger AG, Basel

\section{Introduction}

End-stage renal disease (ESRD) is the most advanced manifestation of chronic kidney disease (CKD). As the population ages and prevalence rates of type 2 diabetes increase, ESRD is set to be an increasing global problem. Worldwide, there are over 1 million patients with ESRD requiring dialysis, with an incidence of about a quarter of a million new patients each year [1]. Patients with ESRD have higher rates of hospitalisation than individuals without the disease $[2,3]$. In the USA, treating patients with ESRD costs approximately USD 18 billion (6.6\% of the Medicare budget) [3].

\section{KARGER}

Fax +41613061234 E-Mail karger@karger.ch www.karger.com

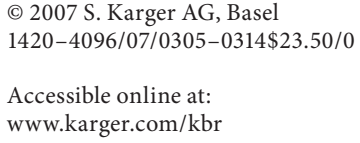

Professor Bengt Fellström

Department of Medical Science, Renal Unit, University Hospital

SE-751 85 Uppsala (Sweden)

Tel. +4618 611 0000, ext. 4348, Fax +461838304

E-Mail bengt.fellstrom@medsci.uu.se 
Cardiovascular disease (CVD) is highly prevalent in patients with ESRD and it is the single largest cause of premature mortality in this patient group [4-7]. Controlling CVD risk factors in patients with ESRD has the potential to lower associated morbidity and mortality, and to thereby decrease the substantial burden on healthcare professionals and providers.

Several landmark trials have established the beneficial effect of statins (hydroxy-methylglutaryl-coenzyme A reductase inhibitors) in reducing cardiovascular morbidity and mortality [8-16]. Reductions in cardiovascular events have also been observed in patients treated with statins, but who do not have elevated cholesterol levels $[13,15,16]$. In addition, in the Heart Protection Study, the benefit of statin treatment was shown to be independent of baseline cholesterol levels [13].

Most patients on haemodialysis do not have elevated total cholesterol (TC) or low-density lipoprotein cholesterol (LDL-C) levels but they have other atherogenic lipid abnormalities, including low high-density lipoprotein cholesterol (HDL-C), elevated triglycerides (TG) and a higher proportion of intermediate and small, dense LDL particles [17-19]. In addition, oxidative stress, endothelial dysfunction and inflammation are all associated with decreasing renal function and dialysis in patients with ESRD [20-23], conditions that can help to promote atherosclerotic disease. As well as lowering LDL-C levels, statins have beneficial effects on other lipid parameters and have other (pleiotropic) effects, including anti-oxidant effects, improving endothelial dysfunction and lowering levels of C-reactive protein (CRP) [24-26].

Patients with ESRD have usually been excluded from outcome studies of statins because of their related comorbidities and issues over safety and pharmacokinetics, leading to a scarcity of clinical characteristics and outcome data for these patients. Moreover, very little comprehensive global prospective data of this kind is available for patients with ESRD undergoing chronic haemodialysis. However, observational data indicate that statin treatment may improve survival in patients with ESRD [27] and large-scale randomised studies with statins in this patient group are required to confirm these findings [28].

In Die Deutsche Diabetes Dialyse Studie (4D study), the effect of atorvastatin $20 \mathrm{mg}$ compared with placebo on cardiovascular outcomes was assessed in 1,255 patients with type 2 diabetes receiving haemodialysis [29]. Atorvastatin did not significantly lower the incidence of the composite primary endpoint (death from cardiac causes, non-fatal myocardial infarction [MI], or fatal or non-fatal stroke), although there were fewer events in the atorvastatin group (226 vs. 243 in the placebo group; relative risk [RR] 0.92, 95\% confidence intervals [CI] 0.77$1.10 ; \mathrm{p}=0.37)$. Cases of fatal stroke occurred significantly more frequently in the atorvastatin group compared with the placebo group (RR 2.03, 95\% CI 1.05-3.93; p = 0.04 ), contributing to the finding that the treatment effect on the primary endpoint was less than predicted. Atorvastatin reduced the rate of all cardiac events combined, compared with the placebo group (RR $0.82,95 \%$ CI $0.68-$ $0.99 ; \mathrm{p}=0.03$ ).

There is a clear need for further long-term studies of patients with ESRD to clarify the role of statins on cardiovascular outcomes. Rosuvastatin is the most effective of the available statins for lowering LDL-C levels, as well as having benefits across the lipid profile $[30,31]$. These properties make it an ideal agent for a study to investigate the benefits of statin treatment for the prevention of cardiovascular events in a population of patients at high risk of these events.

AURORA (A study to evaluate the Use of Rosuvastatin in subjects On Regular haemodialysis: an Assessment of survival and cardiovascular events) is the first large-scale international trial to assess the effects of a statin on cardiovascular morbidity and mortality in patients with ESRD on chronic haemodialysis, irrespective of baseline lipid levels. This report presents preliminary baseline data for patients randomised into the study.

\section{Methods}

Detailed methodology and the rationale for the AURORA study have been published previously [32].

Study Design

AURORA is a randomised, double-blind, multicentre, parallel-group, international, phase IIIb study (fig. 1). Patients have been randomised into the study from 280 centres in 25 countries (table 1). They have been randomised (1:1) to receive either rosuvastatin $10 \mathrm{mg}$ or placebo and are being assessed at regular intervals during the study.

The study is being conducted in accordance with the ethical principles of the Declaration of Helsinki, the International Conference of Harmonisation Good Clinical Practice guidelines and local regulatory requirements. All randomised patients provided written informed consent.

Patients

Men and women aged 50-80 years with ESRD and receiving regular chronic haemodialysis (inclusive of haemofiltration and haemodiafiltration) for at least 3 months were screened for eligibility. 
Fig. 1. AURORA study design. Adapted from Fellström et al. [32] (BioMed Central Open Access article).

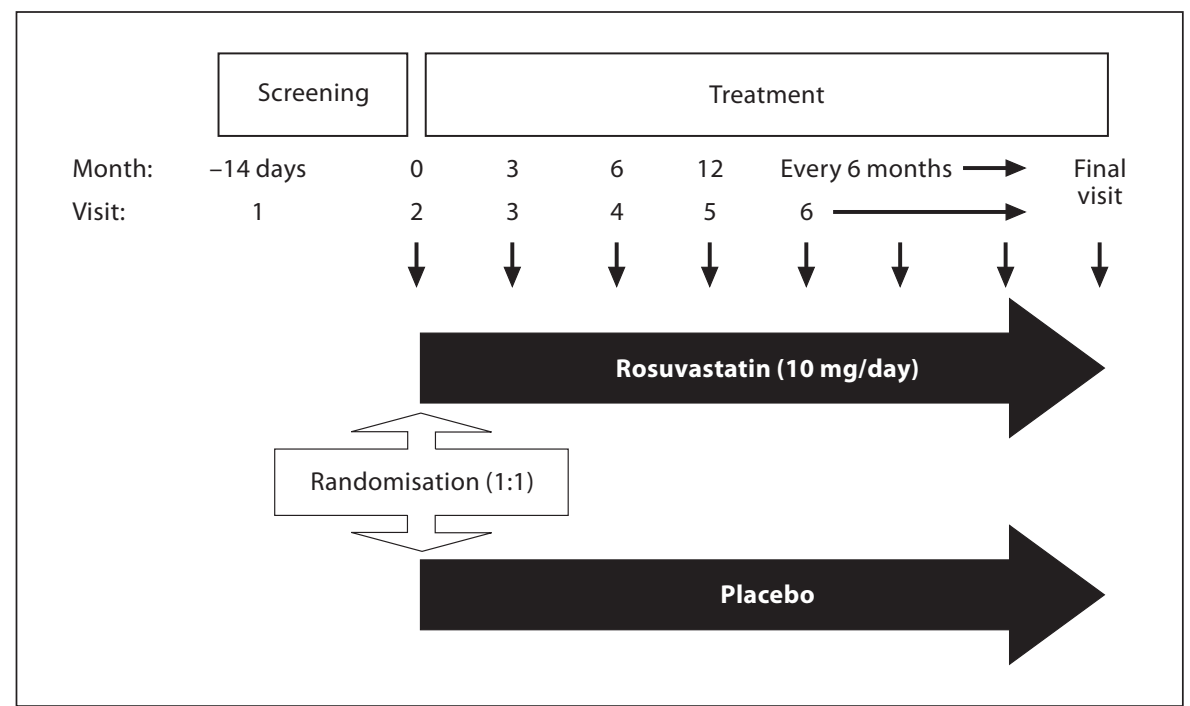

Major exclusion criteria included the likely requirement for kidney transplantation within 1 year; major haematological, neoplastic, metabolic (excluding diabetes), gastrointestinal or infectious disease that may reduce survival to $<1$ year; history of malignancy; statin therapy within the previous 6 months; active liver disease (alanine aminotransferase $>3 \times$ the upper limit of normal [ULN]); uncontrolled hypothyroidism (thyroid-stimulating hormone $>1.5 \times \mathrm{ULN}$ ); and unexplained creatine kinase $>3 \times$ ULN.

\section{Endpoints}

The efficacy endpoints will be analysed using the intentionto-treat population, which includes all randomised patients. Details of specific statistical analyses have been described previously [32].

The primary endpoint is the time to a major cardiovascular event (cardiovascular death, non-fatal MI or non-fatal stroke). All deaths, MIs and strokes are being reviewed and adjudicated by a Clinical Endpoint Committee (in a blinded manner) to ensure consistency of event diagnosis.

Secondary endpoints include all-cause mortality, cardiovascular event-free survival (cardiovascular death, non-fatal MI, non-fatal stroke or death from any other cause), cardiovascular death, noncardiovascular death, procedures as a result of stenosis or thrombosis of the vascular access for chronic haemodialysis (arteriovenous fistulas and grafts only), and coronary or peripheral revascularisations. In addition, the health economic impact of rosuvastatin treatment will be analysed.

In subsequent studies and pre-specified subgroup analyses, the assessment of the prognostic value of various blood markers (CRP, lipid parameters, parathormone, vitamin $\mathrm{D}_{3}$, calcium phosphate product, asymmetrical dimethylarginine [ADMA], B-type natruiretic peptide [BNP], pregnancy-associated plasma protein A [PAPP-A], cardiotrophins and collagen parameters) and the potential interaction with rosuvastatin is planned. A sub-study on telomere length is also intended. Furthermore, the effect of mean systolic and diastolic blood pressure, and pulse pressure on the
Table 1. Distribution of randomised patients by country

\begin{tabular}{lrl}
\hline Country & $\mathrm{n}$ & $\%$ \\
\hline Brazil & 253 & 9.1 \\
UK & 228 & 8.2 \\
France & 216 & 7.8 \\
Canada & 178 & 6.4 \\
Poland & 167 & 6.0 \\
Germany & 165 & 5.9 \\
Australia & 164 & 5.9 \\
The Netherlands & 151 & 5.4 \\
Hungary & 149 & 5.4 \\
Sweden & 109 & 3.9 \\
Denmark & 108 & 3.9 \\
Czech Republic & 99 & 3.6 \\
Turkey & 96 & 3.5 \\
Mexico & 93 & 3.4 \\
Austria & 91 & 3.3 \\
Belgium & 89 & 3.2 \\
South Korea & 82 & 3.0 \\
Bulgaria & 76 & 2.7 \\
Italy & 74 & 2.7 \\
Finland & 69 & 2.5 \\
Norway & 50 & 1.8 \\
Greece & 44 & 1.6 \\
Switzerland & 14 & 0.5 \\
Iceland & 5 & 0.2 \\
Republic of Ireland & 5 & 0.2 \\
\hline Total & 2,775 & \\
& & \\
& &
\end{tabular}




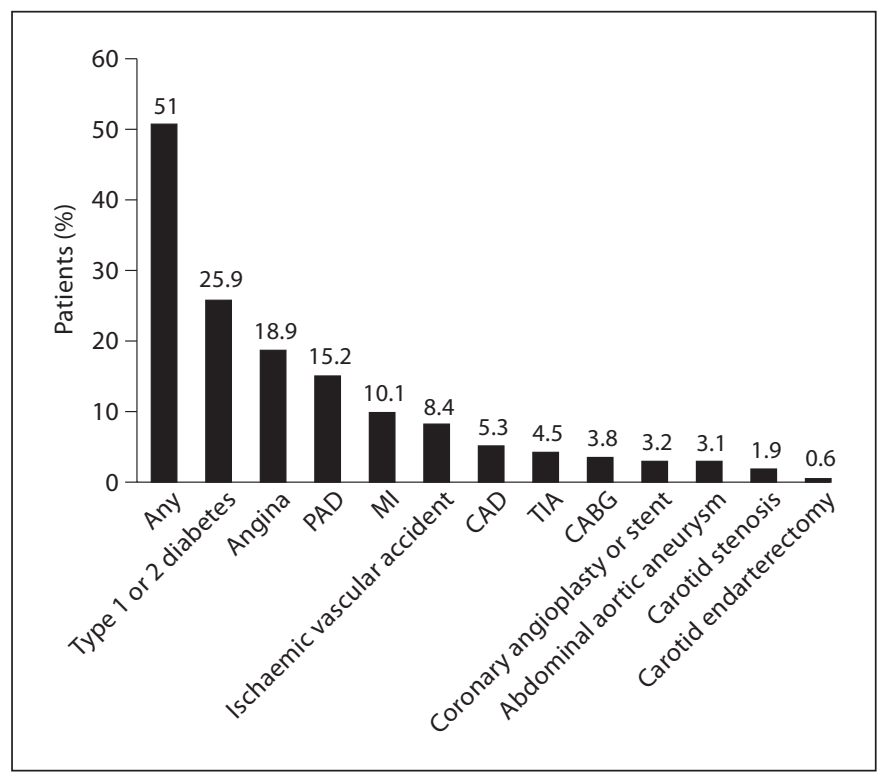

Fig. 2. Prevalence of documented cardiovascular disease or risk equivalent at baseline. Y-axis truncated to $60 \%$ to improve the clarity of the data presented. Any = At least one cardiovascular disease or CVD risk equivalent; $\mathrm{MI}=$ myocardial infarction; $\mathrm{CABG}=$ coronary artery bypass graft $\mathrm{PAD}=$ peripheral arterial disease CAD = carotid artery disease; $\mathrm{TIA}=$ transient ischaemic attack.

primary and secondary variables will be performed in detail, with specific consideration of the potential impact of rosuvastatin.

\section{Statistical Analysis} [32].

The statistical methodology has been published previously

The Executive Steering Committee recently re-evaluated the underlying assumptions of the AURORA study in the light of recently reported studies in similar populations, particularly the 4D [29] and Assessment of LEscol in Renal Transplantation (ALERT) trials [33]. Although these studies observed a substantial reduction in the risk of MI with lipid-lowering therapy, no reduction was observed on stroke. This may indicate the presence of a nonmodifiable endpoint in the composite primary endpoints of these studies. Therefore, the Executive Steering Committee recommended an assumption of a neutral (0\%) treatment effect on strokes and that the assumed placebo annual event rate should be adjusted in line with the observed annual event rate and the revised overall expected treatment effect. These changes were also endorsed by the full Steering Committee.

These modifications were considered scientifically reasonable and necessary given the importance of the study to the medical community. The independent Data and Safety Monitoring Board (DSMB) supported these recommendations and the protocol was consequently amended, thus extending the study by an expected 7 months.

The revised sample size was therefore based upon an assumed cardiovascular event rate of $12 \%$ per year in the placebo group. To detect a $19.5 \%$ reduction in cardiovascular event rate per year at a two-sided significance level of $4.719 \%$ (5\% level adjusted for the interim analysis), with $87 \%$ power, the study should continue until approximately 805 patients have experienced a major cardiovascular event. This is expected to be 4.6 years after initiation of the study, which began in January 2003.

\section{Interim Analysis}

The DSMB performed an interim analysis when 305 patients had experienced a major cardiovascular event, as specified in the original protocol. All endpoints that occurred before or on March 17, 2005 were included in the analysis. The purpose was to investigate the possibility of concluding a significant difference between treatments for the time from randomisation to a major cardiovascular event. Following the interim analysis, the DSMB recommended to the Steering Committee and the study sponsor for the study to continue as planned.

\section{Results}

The AURORA study began in January 2003 and the last patient was randomised in December 2004. From approximately 3,020 patients who entered the screening period, 2,775 patients were randomised into the study from 25 countries in Europe, the Americas and Australasia (table 1).

Baseline characteristics of the patient population are shown in tables 2-4 and figure 2. Male patients comprised $62 \%$ of the population studied, and most patients were white. Mean age of the study population was 64 years, with patients aged between 50-59, 60-69 and 7080 years equally represented. Mean body mass index (BMI) was $25 \mathrm{~kg} / \mathrm{m}^{2}$, with $301(11 \%)$ patients $<20 \mathrm{~kg} / \mathrm{m}^{2}$ and $430(15.5 \%)$ patients $\geq 30 \mathrm{~kg} / \mathrm{m}^{2}$. Fifteen percent of patients were smokers. Mean systolic and diastolic blood pressure was 137 and $76 \mathrm{~mm} \mathrm{Hg}$, respectively (table 2).

The median time since commencing renal replacement therapy was 32 months with just under half (47\%) of all patients on therapy for $<2.5$ years. A total of 2,547 (92\%) patients were receiving standard haemodialysis and 228 (8\%) patients were receiving haemofiltration/haemodiafiltration; the most common type of access was by arteriovenous fistula (79\% patients). Most patients (75\%) were spending from 10 to $14 \mathrm{~h}$ per week on dialysis (table 3 ).

Just over half $(51 \%)$ of the patients had a history of documented CVD or CVD risk equivalent, with diabetes, angina and peripheral arterial disease recorded most frequently (26, 19 and 15\%, respectively) (fig. 2).

Baseline laboratory parameters are shown in table 4 . Mean TC and LDL-C levels were $4.53 \mathrm{mmol} / \mathrm{l}(175 \mathrm{mg} /$ $\mathrm{dl})$ and $2.57 \mathrm{mmol} / \mathrm{l}(99 \mathrm{mg} / \mathrm{dl})$, respectively, and mean 
Table 2. Characteristics of patients at baseline

\begin{tabular}{lc}
\hline & $\begin{array}{c}\text { Randomised population } \\
(\mathrm{n}=2,775)\end{array}$ \\
\hline Male, $\mathrm{n}(\%)$ & $1,724(62.1)$ \\
Mean age, years (SD) & $64.2(8.7)$ \\
Age group, $\mathrm{n}(\%)$ & \\
$\quad<50$ years & \\
$50-59$ years & $3(0.1)$ \\
60-69 years & $968(34.9)$ \\
$70-80$ years & $900(32.4)$ \\
$>80$ years & $901(32.5)$ \\
Race, $\mathrm{n}(\%)$ & $3(0.1)$ \\
White & \\
Black & $2,356(84.9)$ \\
Asian & $98(3.5)$ \\
Hispanic & $139(5.0)$ \\
Other & $113(4.1)$ \\
Mean BMI, kg/m ${ }^{2}$ (SD) & $69(2.5)$ \\
Mean blood pressure, mm Hg (SD) & $25.4(4.9)$ \\
Systolic & $136.9(24.5)$ \\
Diastolic & $75.8(12.7)$ \\
Pulse pressure & $61.2(19.4)$ \\
Smoker, $\mathrm{n}(\%)$ & $429(15.5)$ \\
Major cardiovascular disease or risk equivalents, $\mathrm{n}(\%)$ \\
Type 1 or 2 diabetes & $718(25.9)$ \\
Angina & $524(18.9)$ \\
Peripheral arterial disease & $422(15.2)$ \\
Myocardial infarction & $281(10.1)$ \\
\hline
\end{tabular}

a Protocol deviators.

HDL-C and TG levels were $1.16 \mathrm{mmol} / \mathrm{l}(45 \mathrm{mg} / \mathrm{dl})$ and $1.75 \mathrm{mmol} / \mathrm{l}(155 \mathrm{mg} / \mathrm{dl})$, respectively. Mean haemoglobin and haematocrit levels were within the target range recommended by international guidelines for patients with CKD $[35,36]$.

\section{Discussion}

AURORA is the first large-scale prospective international trial to assess the effects of a statin on cardiovascular morbidity and mortality in ESRD patients on chronic haemodialysis, irrespective of baseline lipid levels. It will provide the largest database of its kind, with structured, prospective data collection and all primary endpoints being adjudicated by a Clinical Endpoint Committee. AURORA has the potential to provide a representative picture of the effect of statin therapy on cardiovascular morbidity and mortality in patients on chronic haemodialysis.
Table 3. Dialysis parameters at baseline

\begin{tabular}{|c|c|}
\hline & $\begin{array}{l}\text { Randomised } \\
\text { population } \\
(\mathrm{n}=2,775)\end{array}$ \\
\hline Median time since RRT started, months & 32.0 \\
\hline \multicolumn{2}{|l|}{ Categories, $\mathrm{n}(\%)$} \\
\hline Unknown & $1(0.04)$ \\
\hline 0 to $<2.5$ years & $1,306(47.1)$ \\
\hline 2.5 to $<5.0$ years & $687(24.8)$ \\
\hline 5.0 to $<7.5$ years & $343(12.4)$ \\
\hline 7.5 to $<10.0$ years & $140(5.0)$ \\
\hline$\geq 10.0$ years & $298(10.7)$ \\
\hline Median time since haemodialysis started, months & 28.0 \\
\hline \multicolumn{2}{|l|}{ Categories, $\mathrm{n}(\%)$} \\
\hline Unknown & $1(0.04)$ \\
\hline 0 to $<2.5$ years & $1,467(52.9)$ \\
\hline 2.5 to $<5.0$ years & $699(25.2)$ \\
\hline 5.0 to $<7.5$ years & $320(11.5)$ \\
\hline 7.5 to $<10.0$ years & $122(4.4)$ \\
\hline$\geq 10.0$ years & $166(6.0)$ \\
\hline \multicolumn{2}{|l|}{ Current dialysis treatment, $\mathrm{n}(\%)$} \\
\hline Haemodialysis & $2,547(91.8)$ \\
\hline Haemofiltration/haemodiafiltration & $228(8.2)$ \\
\hline \multicolumn{2}{|l|}{ Filters/membranes, $\mathrm{n}(\%)$} \\
\hline High flux & $1,210(43.6)$ \\
\hline Low flux & $1,565(56.4)$ \\
\hline \multicolumn{2}{|l|}{ Type of access, n (\%) } \\
\hline Arteriovenous fistula & $2,202(79.4)$ \\
\hline Central dialysis catheter & $316(11.4)$ \\
\hline Graft & $239(8.6)$ \\
\hline Not recorded & $18(0.6)$ \\
\hline \multicolumn{2}{|l|}{ Duration of dialysis } \\
\hline Mean (SD), h/week & $11.9(1.8)$ \\
\hline \multicolumn{2}{|l|}{ Categories, n (\%) } \\
\hline$<10 \mathrm{~h} /$ week & $295(10.6)$ \\
\hline$\geq 10$ to $<14 \mathrm{~h} /$ week & $2,077(74.8)$ \\
\hline$\geq 14$ h/week & $402(14.5)$ \\
\hline Not recorded & $1(0.04)$ \\
\hline Calculated Kt/V, mean (SD) & $1.547(0.369)$ \\
\hline
\end{tabular}

$\mathrm{RRT}=$ Renal replacement therapy; Kt/V = dialysis adequacy calculated from pre- and post-urea results [34].

Documented CVD and/or diabetes were present in half of the patients. The main lipid parameters at baseline were close to those observed in other studies of haemodialysis populations [19, 37, 38], although they did appear to differ from those reported in the 4D study: Mean \pm SD baseline lipid levels in 4D: TC $220 \pm 42 \mathrm{mg} / \mathrm{dl}$ in placebo and $218 \pm 43 \mathrm{mg} / \mathrm{dl}$ in atorvastatin patients, LDL-C $127 \pm 30 \mathrm{mg} / \mathrm{dl}$ in placebo and $125 \pm 29 \mathrm{mg} / \mathrm{dl}$ in atorvastatin patients and TG $267 \pm 168 \mathrm{mg} / \mathrm{dl}$ in placebo and $261 \pm 165 \mathrm{mg} / \mathrm{dl}$ in atorvastatin patients - all higher lev- 
els than in the AURORA patients at baseline; HDL-C was $36 \pm 14 \mathrm{mg} / \mathrm{dl}$ in placebo and $36 \pm 13 \mathrm{mg} / \mathrm{dl}$ in atorvastatin patients - lower than in AURORA patients at baseline $[29,39]$. The difference in lipids at baseline between $4 \mathrm{D}$ and AURORA may be due to differing inclusion criteria: $4 \mathrm{D}$ only randomised patients with type 2 diabetes and excluded patients with fasting serum LDL-C levels of less than $80 \mathrm{mg} / \mathrm{dl}(2.1 \mathrm{mmol} / \mathrm{l})$ or more than $190 \mathrm{mg} / \mathrm{dl}$ ( $4.9 \mathrm{mmol} / \mathrm{l})$, whereas AURORA did not specify LDL-C levels or a history of diabetes in its inclusion criteria.

Mean baseline oxidised LDL levels (34.2 U/1) in AURORA were below levels previously observed in apparently healthy, middle-aged men from the general population (93 U/l) [40]. Diepeveen et al. [41] also report mean oxidised LDL levels in dialysis patients to be below those expected for the general population ( $42 \mathrm{U} / \mathrm{l}$ at baseline in the placebo arm), and they indicated that this may reflect the lower lipid levels present in these patients (mean \pm $\mathrm{SD})$, baseline LDL-C $2.7 \pm 0.8 \mathrm{mmol} / \mathrm{l}$ in the placebo arm), which are similar to the baseline LDL-C levels in AURORA.

Outcome trials of statins in patients with conditions related to the disease profile of those enrolled in the AURORA trial include 4D [29, 39], ALERT [33] and SHARP (Study of Heart And Renal Protection [42]).

Data from the $4 \mathrm{D}$ study indicate the absence of a significant beneficial effect of atorvastatin on cardiovascular outcomes in patients with diabetes receiving haemodialysis, although a significant reduction in cardiac events was observed (RR 0.82, 95\% CI 0.68-0.99; $\mathrm{p}=0.03$ ). Cases of fatal stroke were observed more frequently in the atorvastatin group compared with the placebo group, although the number of these (27 [4\%] and 13 [2\%] of patients, respectively) was low. Atorvastatin significantly reduced the secondary endpoint of all cardiac events combined, compared with the placebo group (246 vs. 205 in the placebo group; RR $0.82,95 \%$ CI $0.68-0.99$;

Table 4. Lipid and other laboratory parameters at baseline, mean (SD)

\begin{tabular}{lcr}
\hline & $\mathrm{mmol} / \mathrm{l}$ & $\mathrm{mg} / \mathrm{dl}$ \\
\hline Total cholesterol & $4.53 \pm 1.09$ & $175 \pm 42$ \\
LDL-C & $2.57 \pm 0.89$ & $99 \pm 34$ \\
HDL-C & $1.16 \pm 0.40$ & $45 \pm 15$ \\
Triglycerides & $1.75 \pm 1.06$ & $155 \pm 93$ \\
\hline ApoB, mg/dl & $81.7 \pm 24.4$ \\
ApoA-I, mg/dl & $121.7 \pm 27.1$ \\
ApoB/ApoA-I ratio & $0.700 \pm 0.250$ \\
Oxidised LDL, U/l & $34.2 \pm 13.8$ \\
Haemoglobin, g/dl & $11.68 \pm 1.60$ \\
Haematocrit, vol\% & $35.0 \pm 4.9$ \\
Albumin, g/l & $39.7 \pm 3.5$ \\
Calcium, mmol/l & $2.343 \pm 0.220$ \\
Phosphate, mmol/l & $1.793 \pm 0.550$ \\
\hline
\end{tabular}

To convert $\mathrm{mg} / \mathrm{dl}$ to $\mathrm{mmol} / \mathrm{l}$, multiply by 0.02586 for cholesterol and by 0.01129 for triglycerides.

Table 5. Comparison of study design and baseline entry criteria for the $4 \mathrm{D}[29,39]$ and AURORA studies

\begin{tabular}{lll}
\hline & $4 \mathrm{D}$ & AURORA \\
\hline Countries & 1 (Germany) & 25 \\
Randomised patients, $\mathrm{n}$ & 1,225 & 2,775 \\
Age group & $18-80$ years & $50-80$ years \\
Length of dialysis treatment & $\leq 2$ years & $\geq 3$ months \\
LDL-C, mmol/l $(\mathrm{mg} / \mathrm{dl})$ & $2.1-4.9(80-190)$ & not specified \\
TG, mmol/l $(\mathrm{mg} / \mathrm{dl})$ & $\leq 11.3(1,000)$ & not specified \\
History of diabetes & Yes & not required \\
Duration of study & 4 years ${ }^{\text {a }}$ & $\sim 4.6$ years \\
Study drug & atorvastatin 20 mg & rosuvastatin 10 mg \\
Primary endpoint & composite of death from cardiac causes, & major cardiovascular event (i.e. non-fatal MI, \\
& fatal stroke, non-fatal MI, or non-fatal stroke & non-fatal stroke or cardiovascular death) \\
Study design & national (Germany), multicentre, randomised, & international, multicentre, randomised, double- \\
& double-blind, placebo controlled, parallel group & blind, placebo controlled, parallel group
\end{tabular}

${ }^{a}$ Mean follow-up. ${ }^{b}$ From first patient enrolled to last patient out.

To convert $\mathrm{mg} / \mathrm{dl}$ to $\mathrm{mmol} / \mathrm{l}$, multiply by 0.02586 for cholesterol and by 0.01129 for TG. 
$\mathrm{p}=0.03)$. Other individual components of the primary endpoint and other secondary endpoints (e.g. death from all causes and all cerebrovascular events combined) did not differ significantly between the atorvastatin and placebo groups. The absence of a stroke benefit and the increase in fatal strokes led the investigators to speculate that the pathogenesis of vascular events in diabetes mellitus patients who are receiving dialysis may, at least in part, be different from that in patients without ESRD.

The study design and patient populations in AURORA and $4 \mathrm{D}$ differ in several respects (table 5). First, patients with diabetes (type 1 or 2) comprised $26 \%$ of the AURORA patient group (fig. 2), whereas all patients in the $4 \mathrm{D}$ study had type 2 diabetes. Second, patients were eligible for AURORA irrespective of their lipid profile and mean lipid levels were markedly lower than in the $4 \mathrm{D}$ population (table 5). Third, there was no upper limit on the duration of haemodialysis for inclusion in AURORA whereas patients in $4 \mathrm{D}$ were required to have been receiving haemodialysis for less than 2 years (mean duration approximately 8 months). Fourth, AURORA randomised 2,775 patients from 25 different countries whereas $4 \mathrm{D}$ was conducted in fewer patients $(1,255)$ from a single country (Germany). Fifth, the statin treatment in both studies differed. Statin treatment in AURORA is rosuvastatin $10 \mathrm{mg}$ once daily and in $4 \mathrm{D}$ it was atorvastatin $20 \mathrm{mg}$ once daily (both studies had a placebo arm). Finally, although the lower age limit for inclusion in AURORA was 50 years, the mean age (64.2 years; SD 8.7) was similar to that in the $4 \mathrm{D}$ study (65.7 years; SD 8.3), which recruited patients aged $\geq 18$ years.

The ALERT trial assessed the effects of fluvastatin therapy in renal transplant recipients [33], for whom cardiovascular risk is considerably decreased compared with patients with ERSD [4]. Although the 17\% risk reduction (112 vs. 134 events) with fluvastatin versus placebo for the primary endpoint (occurrence of a major adverse cardiac event) was not significant, there were significantly fewer cardiac deaths or non-fatal MIs (35\% risk reduction vs. placebo; 70 vs. 104 events, $\mathrm{p}<0.005$ ). In both groups (fluvastatin and placebo), $15 \%$ had experienced a cardiac, cerebrovascular or other vascular event at baseline, which was lower than the predicted rate, leading to insufficient power to detect a significant reduction in the primary endpoint. In the ALERT extension study, patients receiving fluvastatin had a significant reduction in the relative risks of a major adverse cardiac event (risk reduction, $21 \% ; 137$ vs. 174 events; $\mathrm{p}=0.036$ ) and of a cardiac death or non-fatal MI (risk reduction 29\%; 95 vs. 128 events; $\mathrm{p}=0.014)$ compared with placebo [43].
The ongoing SHARP study is investigating the effect of simvastatin and ezetimibe on the frequency of major cardiovascular events in $\sim 9,000$ patients with CKD ( $\sim 3,000$ on dialysis) who do not have established coronary heart disease [42]. The study commenced in July 2003 and is expected to complete in December 2010.

The effects of rosuvastatin $10 \mathrm{mg}$ and atorvastatin 20 $\mathrm{mg}$ on a range of lipid levels in high-risk patients with hypercholesterolaemia were assessed in the PULSAR (Prospective study to evaluate the Utility of Low doses of the Statins Atorvastatin and Rosuvastatin) trial. Rosuvastatin was significantly more effective than atorvastatin at improving LDL-C levels $(-45 \%$ vs. $-43 \%$ mean change from baseline; $\mathrm{p}=0.05)$ and HDL-C levels $(6.4 \%$ vs. $3.1 \%$ mean change from baseline; $p<0.001$ ) in this patient group [44].

The recently reported Stroke Prevention by Aggressive Reduction in Cholesterol Levels (SPARCL) study assessed the effects of atorvastatin $80 \mathrm{mg}$ on patients with no known coronary heart disease who had experienced a stroke or transient ischaemic attack (TIA) within 1-6 months of study entry. The study followed 4,731 patients over 5 years and found that atorvastatin reduced the overall incidence of both stroke (absolute reduction in risk $2.2 \%, \mathrm{p}=0.03$ ) and cardiovascular events (absolute reduction in risk $3.5 \%, \mathrm{p}=0.002$ ) compared with placebo, despite a small increase in the number of hemorrhagic strokes. Baseline TC, LDL-C and HDL-C lipid levels were higher and TG levels were lower in SPARCL patients compared with AURORA patients [45]. The specific effects on stroke that may occur in AURORA, although the AURORA study was not designed to elicit them, could help to understand the conflicting outcomes on stroke seen in the SPARCL and 4D studies.

Rosuvastatin is the most effective statin for lowering LDL-C [46-48] and, in AURORA, it is expected that LDL-C will be reduced to levels below those previously achieved in other statin outcomes studies, due to the low baseline values in this population.

In conclusion, preliminary baseline data from the AURORA study show a representative population of patients with ESRD receiving haemodialysis. The expected results from this study have the potential to show the effect of statin therapy in improving cardiovascular outcomes in patients with ESRD and will help guide the optimal management of this patient population. 


\section{Acknowledgements}

We gratefully acknowledge the invaluable contributions of the Steering Committee, the Data and Safety Monitoring Board, the Clinical Endpoint Committee and all investigators and coordinators to the implementation of this study. We would also like to thank Dr. Margaret Duggan-Keen and Shirley Smith, from Prime Medica, who provided medical writing support on behalf of AstraZeneca.

\section{Appendix}

Executive Steering Committee

Professor B. Fellström (Principal Investigator; Uppsala, Sweden), Professor F. Zannad (Toul, France), Professor R. Schmieder (Erlangen, Germany), Dr. H. Holdaas (Oslo, Norway), Professor A. Jardine (Glasgow, UK).

\section{Steering Committee}

Executive Steering Committee members plus Dr. K. Bannister (Adelaide, Australia), Dr. J. Beutler (Den Bosch, The Nether- lands), Professor D. Chae (Kyungki-Do, Seoul, South Korea), Professor S.M. Cobbe (Glasgow, UK), Professor C. Gronhagen-Riska (Helsinki, Finland), Dr. J. Lima (Sao Paulo, Brazil), Professor R. Lins (Antwerpen, Belgium), Dr. A. McMahon (Edmonton, Canada), Professor G. Mayer (Innsbruck, Austria), Professor H.-H. Parving (Gentofte, Denmark), Dr. C. Ramos (San Luis Potosí, Mexico), Professor G. Remuzzi (Bergamo, Italy), Professor O. Samuelsson (Goteborg, Sweden), Professor S. Sonkodi (Szeged, Hungary), Dr. G. Suleymanlar (Antalya, Turkey), Professor V. Tesar (Prague, Czech Republic), Dr. D. Tsakiris (Veria, Greece), Professor V. Todorov (Pleven, Bulgaria), Professor A. Wiecek (Katowice, Poland), Professor R. Wüthrich (St. Gallen, Switzerland).

\section{Data and Safety Monitoring Board}

Professor H. Dargie (Chair; Glasgow, UK), Professor E. Ritz (Heidelberg, Germany), Professor H. Wedel (Goteborg, Sweden), Professor A.H. Zwinderman (Amsterdam, The Netherlands).

\section{Clinical Endpoint Committee}

Professor S.M. Cobbe (Chair; Glasgow, UK), Dr. A. Brady (Glasgow, UK), Dr. C. Deighan (Glasgow, UK), Professor P. Macfarlane (Glasgow, UK), Professor D. Stott (Glasgow, UK).

\section{References}

1 Moeller S, Gioberge S, Brown G: ESRD patients in 2001: global overview of patients, treatment modalities and development trends. Nephrol Dial Tranplant 2002;17: 2071-2076.

2 Go AS, Chertow GM, Fan D, McCulloch CE, Hsu CY: Chronic kidney disease and the risks of death, cardiovascular events and hospitalization. N Engl J Med 2004;351: 1296-1305.

3 US Renal Data System: Annual Data Report. Bethesda, National Institutes of Health, National Institute of Diabetes and Digestive and Kidney Diseases, 2005.

4 Foley RN, Parfrey PS, Sarnak MJ: Clinical epidemiology of cardiovascular disease in chronic renal disease. Am J Kidney Dis 1998; 32:S112-S119.

$\checkmark 5$ Parfrey PS: Cardiac disease in dialysis patients: diagnosis, burden of disease, prognosis, risk factors and management. Nephrol Dial Transplant 2000;15(suppl 5):58-68.

6 Levey AS, Beto JA, Coronado BE, Eknoyan G, Foley RN, Kasiske BL, Klag MJ, Mailloux LU, Manske CL, Meyer KB, Parfrey PS, Pfeffer MA, Wenger NK, Wilson PW, Wright JT Jr: Controlling the epidemic of cardiovascular disease in chronic renal disease: What do we know? What do we need to learn? Where do we go from here? National Kidney Foundation Task Force on Cardiovascular Disease. Am J Kidney Dis 1998;32:853-906.

7 Mackay J, Mensah GA: The Atlas of Heart Disease and Stroke. Geneva, World Health Organization, 2004.
-8 4S (Scandinavian Simvastatin Survival Study Group): Randomised trial of cholesterol lowering in 4,444 patients with coronary heart disease: the Scandinavian Simvastatin Survival Study (4S). Lancet 1994; 344:1383-1389.

-9 Shepherd J, Cobbe SM, Ford I, Isles CG, Lorimer AR, MacFarlane PW, McKillop JH, Packard CJ; West of Scotland Coronary Prevention Study Group: Prevention of coronary heart disease with pravastatin in men with hypercholesterolemia. N Engl J Med 1995;333:1301-1307.

-10 Sacks FM, Pfeffer MA, Moye LA, Rouleau JL, Rutherford JD, Cole TG, Brown L, Warnica JW, Arnold JM, Wun CC, Davis BR, Braunwald E: The effect of pravastatin on coronary events after myocardial infarction in patients with average cholesterol levels. Cholesterol and Recurrent Events Trial Investigators. N Engl J Med 1996;335:1001-1009.

11 Downs JR, Clearfield M, Weis S, Whitney E, Shapiro DR, Beere PA, Langendorfer A, Stein EA, Kruyer W, Gotto AM Jr: Primary prevention of acute coronary events with lovastatin in men and women with average cholesterol levels. Results of AFCAPS/TexCAPS Air Force/Texas Coronary Atherosclerosis Prevention Study. JAMA 1998;279:16151622.

12 The Long-term Intervention with Pravastatin in Ischemic Disease (LIPID) Study Group: Prevention of cardiovascular events and death with pravastatin in patients with coronary heart disease and a broad range of initial cholesterol levels. N Engl J Med 1998; 339:1349-1357.
13 Heart Protection Study Collaborative Group: MRC/BHF Heart Protection Study of cholesterol lowering with simvastatin in 20,536 high-risk individuals: a randomised placebo-controlled trial. Lancet 2002;360:7-22.

14 Shepherd J, Blauw GJ, Murphy MB, Bollen EL, Buckley BM, Cobbe SM, Ford I, Gaw A, Hyland M, Jukema JW, Kamper AM, Macfarlane PW, Meinders AE, Norrie J, Packard CJ, Perry IJ, Stott DJ, Sweeney BJ, Twomey C, Westendorp RG; PROSPER study group: PROspective Study of Pravastatin in the Elderly at Risk. Pravastatin in elderly individuals at risk of vascular disease (PROSPER): a randomised controlled trial. Lancet 2002; 360:1623-1630.

15 Sever PS, Dahlöf B, Poulter NR, Wedel H, Beevers G, Caulfield M, Collins R, Kjeldsen SE, Kristinsson A, McInnes GT, Mehlsen J, Nieminen M, O’Brien E, Östergren J; ASCOT investigators: Prevention of coronary and stroke events with atorvastatin in hypertensive patients who have average or lowerthan-average cholesterol concentrations, in the Anglo-Scandinavian Cardiac Outcomes Trial-Lipid Lowering Arm (ASCOT-LLA): a multicentre randomised controlled trial. Lancet 2003;361:1149-1158.

16 Colhoun HM, Betteridge DJ, Durrington PN, Hitman GA, Neil H, Livingstone S, Thomason MJ, Mackness MI, Charlton-Menys V, Fuller JH; CARDS investigators: Primary prevention of cardiovascular disease with atorvastatin in type 2 diabetes in the Collaborative Atorvastatin Diabetes Study (CARDS): multicentre randomised placebocontrolled trial. Lancet 2004;364:685-696. 
17 Shoji T, Nishizawa Y, Kawagishi T, Tanaka M, Kawasaki K, Tabata T, Inoue T, Morii H: Atherogenic lipoprotein changes in the absence of hyperlipidemia in patients with chronic renal failure treated by hemodialysis. Atherosclerosis 1997;131:229-236.

-18 Shoji T, Nishizawa Y, Kawagishi T, Kawasaki $\mathrm{K}$, Taniwaki H, Tabata T, Inoue T, Morii H: Intermediate-density lipoprotein as an independent risk factor for aortic atherosclerosis in hemodialysis patients. J Am Soc Nephrol 1998;9:1277-1284.

- 19 Deighan CJ, Caslake MJ, McConnell M, Boulton-Jones JM, Packard CJ: Atherogenic lipoprotein phenotype in end-stage renal failure: origin and extent of small dense lowdensity lipoprotein formation. Am J Kidney Dis 2000;35:852-862.

20 Stenvinkel P, Heimburger O, Paultre F, Diczfalusy U, Wang T, Berglund L, Jogestrand T: Strong association between malnutrition, inflammation, and atherosclerosis in chronic renal failure. Kidney Int 1999:55:18991911.

-21 Annuk M, Zilmer M, Lind L, Linde T, Fellstrom B: Oxidative stress and endothelial function in chronic renal failure. J Am Soc Nephrol 2001;12:2747-2752.

-22 Annuk M, Lind L, Linde T, Fellström B: Impaired endothelium-dependent vasodilation in renal failure in humans. Nephrol Dial Transplant 2001;16:302-306.

23 Locatelli F, Canaud B, Eckardt KU, Stenvinkel P, Wanner C, Zoccali C: Oxidative stress in end-stage renal disease: an emerging threat to patient outcome. Nephrol Dial Transplant 2003;18:1272-1280.

24 Laufs U: Beyond lipid-lowering: effects of statins on endothelial nitric oxide. Eur J Clin Pharmacol 2003;58:719-731.

25 Rosenson RS: Statins in atherosclerosis: lipid-lowering agents with antioxidant capabilities. Atherosclerosis 2004;173:1-12.

26 Field KM: Effect of 3-hydroxy-3-methylglutaryl coenzyme A reductase inhibitors on high-sensitivity C-reactive protein levels. Pharmacotherapy 2005;25:1365-1377.

-27 Seliger SL, Weiss NS, Gillen DL, Kestenbaum B, Ball A, Sherrard DJ, Stehman-Breen CO: HMG-CoA reductase inhibitors are associated with reduced mortality in ESRD patients. Kidney Int 2002;61:297-304.

28 National Kidney Foundation: K/DOQI clinical practice guidelines for managing dyslipidemias in chronic kidney disease. Am J Kidney Dis 2003;41(suppl 3):S1-S92.

-29 Wanner C, Krane V, März W, Olschewski M, Mann JF, Ruf G, Ritz E; for the German Diabetes and Dialysis Study Investigators: Atorvastatin in patients with type 2 diabetes mellitus undergoing hemodialysis. N Engl J Med 2005;353:238-242.

30 Blasetto JW, Stein EA, Brown WV, Chitra R, Raza A: Efficacy of rosuvastatin compared with other statins at selected starting doses in hypercholesterolemic patients and in special population groups. Am J Cardiol 2003; 91:3C-10C.
1 Chapman MJ, Caslake M, Packard C, McTaggart F: New dimension of statin action on ApoB atherogenicity. Clin Cardiol 2003;26(1 suppl 1):I7-I10.

-32 Fellström B, Zannad F, Schmieder R, Holdaas H, Jardine A, Rose H, Wilpshaar W; AURORA Study Group: Effect of rosuvastatin on outcomes in chronic haemodialysis patients: design and rationale of the AURORA study. Curr Control Trials Cardiovasc Med 2005;6:9.

33 Holdaas H, Fellström B, Jardine AG, Holme I, Nyberg G, Fauchald P, Gronhagen-Riska C, Madsen S, Neumayer HH, Cole E, Maes B, Ambuhl P, Olsson AG, Hartmann A, Solbu DO, Pedersen TR; Assessment of LEscol in Renal Transplantation (ALERT) Study Investigators: Effect of fluvastatin on cardiac outcomes in renal transplant recipients: a multicentre, randomised, placebo-controlled trial. Lancet 2003;361:2024-2031.

34 Jindal KK, Manuel A, Goldstein MB: Percent reduction in blood urea concentration during hemodialysis (PRU): a simple and accurate method to estimate $\mathrm{Kt} / \mathrm{V}$ urea. ASAIO Trans 1987;33:286-288.

35 National Kidney Foundation: K/DOQI clinical practice guidelines for anemia of chronic kidney disease, 2000. Am J Kidney Dis 2001;27(suppl 1):S182-S238.

36 Locatelli F, Aljama P, Barany P, Canaud B, Carrera F, Eckardt KU, Horl WH, Macdougal IC, Macleod A, Wiecek A, Cameron S; European Best Practice Guidelines Working Group: Revised European best practice guidelines for the management of anaemia in patients with chronic renal failure. Nephrol Dial Transplant 2004;19(suppl 2): iil-ii47.

37 Kronenberg F, Konig P, Neyer U, Auinger M, Pribasnig A, Lang U, Reitinger J, Pinter G, Utermann G, Dieplinger H: Multicenter study of lipoprotein(a) and apolipoprotein(a) phenotypes in patients with end-stage renal disease treated by hemodialysis or continuous ambulatory peritoneal dialysis. J Am Soc Nephrol 1995;6:110-120.

38 Kushiya F, Wada H, Sakakura M, Mori Y, Gabazza EC, Nishikawa M, Nobori T, Noguchi M, Izumi K, Nakasaki T, Takagi M, Shiku $\mathrm{H}$ : Effects of lipid abnormalities on arteriosclerosis and hemostatic markers in patients under hemodialysis. Clin Appl Thromb Hemost 2003;9:203-210.

-39 Wanner C, Krane V, Marz W, Olschewski M, Asmus HG, Kramer W, Kuhn KW, Kutemeyer H, Mann JF, Ruf G, Ritz E; Deutsche Diabetes-Dialyse-Studie (4D) Study Group Randomized controlled trial on the efficacy and safety of atorvastatin in patients with type 2 diabetes on hemodialysis (4D study): demographic and baseline characteristics. Kidney Blood Press Res 2004;27:259-266.

40 Meisinger C Baumert J, Khuseyinova N, Loewel H, Koenig W: Plasma oxidized lowdensity lipoprotein, a strong predictor for acute coronary heart disease events in apparently healthy, middle-aged men from the general population. Circulation 2005;112: 651-657.
41 Diepeveen SH, Verhoeven GW, Van Der Palen J, Dikkeschei LD, Van Tits LJ, Kolsters G, Offerman JJ, Bilo HJ, Stalenhoef AF: Effects of atorvastatin and vitamin $\mathrm{E}$ on lipoproteins and oxidative stress in dialysis patients: a randomised-controlled trial. J Intern Med 2005;257:438-445.

42 Baigent C, Landry M: Study of Heart and Renal Protection (SHARP). Kidney Int 2003; 63(suppl 84):207-210.

43 Holdaas H, Fellström B, Cole E, Nyberg G, Olsson AG, Pedersen TR, Madsen S, Gronhagen-Riska C, Neumayer HH, Maes B, Ambuhl P, Hartmann A, Staffler B, Jardine AG; Assessment of LEscol in Renal Transplantation (ALERT) Study Investigators: Long term cardiac outcomes in renal transplant recipients receiving fluvastatin: the ALERT extension study. Am J Transplant 2005;5: 2929-2936.

44 Clearfield MB, Amerena J, Bassand JP, Garcia HR, Miller SS, Sosef FF, Palmer MK, Bryzinski BS: Comparison of the efficacy and safety of rosuvastatin $10 \mathrm{mg}$ and atorvastatin $20 \mathrm{mg}$ in high-risk patients with hypercholesterolemia: Prospective study to evaluate the Use of Low doses of the Statins Atorvastatin and Rosuvastatin (PULSAR). Trials 2006;7:35.

45 Amarenco P, Bogousslavsky J, Callahan A 3rd, Goldstein LB, Hennerici M, Rudolph AE, Sillesen H, Simunovic L, Szarek M, Welch KM, Zivin JA; Stroke Prevention by Aggressive Reduction in Cholesterol Levels (SPARCL) Investigators: High-dose atorvastatin after stroke or transient ischemic attack. N Engl J Med 2006;355:549-559.

46 Ballantyne CM, Bertolami M, Hernandez Garcia HR, Nul D, Stein EA, Theroux P, Weiss R, Cain VA, Raichlen JS: Achieving LDL cholesterol, non-HDL cholesterol, and apolipoprotein B target levels in high-risk patients: Measuring Effective Reductions in Cholesterol Using Rosuvastatin TherapY (MERCURY) II. Am Heart J 2006;151:975. e1-e9.

47 Jones PH, Davidson MH, Stein EA, Bays HE, McKenney JM, Miller E, Cain VA, Blasetto JW; STELLAR Study Group: Comparison of the efficacy and safety of rosuvastatin versus atorvastatin, simvastatin, and pravastatin across doses (STELLAR Trial). Am J Cardiol 2003;92:152-160.

48 Schuster H, Barter PJ, Stender S, Cheung RC, Bonnet J, Morrell JM, Watkins C, Kallend D, Raza A; Effective Reductions in Cholesterol Using Rosuvastatin Therapy I Study Group: Effects of switching statins on achievement of lipid goals: Measuring Effective Reductions in Cholesterol using Rosuvastatin therapY (MERCURY I) study. Am Heart J 2004; 147:705-712. 